\title{
Dynamics of Architectural and Urban Planning Hospital Systems Evolution
}

\author{
Irina Bulakh ${ }^{1, *}$, Olena Chala ${ }^{2}$, Viktor Divak ${ }^{3}$ \\ ${ }^{1}$ Department of Design Architectural Environment, Kyiv National University of Construction and Architecture, Kyiv, Ukraine \\ ${ }^{2}$ Department of Information Technologies in Architecture, Kyiv National University of Construction and Architecture, Kyiv, Ukraine \\ ${ }^{3}$ Department of Architectural design of civil buildings and structures, Kyiv National University of Construction and Architecture, Kyiv, \\ Ukraine
}

Received May 2, 2020; Revised July 16, 2020; Accepted July 29, 2020

Copyright $\odot 2020$ by authors, all rights reserved. Authors agree that this article remains permanently open access under the terms of the Creative Commons Attribution License 4.0 International License

\begin{abstract}
The article is written as part of a study of the urban planning foundations of the health system spatial development, one of the components of which are hospitals. The article is aimed to study dynamics of architectural and urban planning hospital systems evolution. The study is performed by using systemic and integrated analysis. This article focuses on challenging the issue of historical evolution analysis and further transformation ways of hospital systems in the aspect of architectural and urban planning design. The basic assumptions have been determined and the historical periods of the formation of hospital organizations have been identified. Dynamic regularities are established, the specificity is described and trends of the typological transformation of hospital systems in various regional contexts of the world`s major countries are indicated. The study was carried out taking into account the conformity to the laws of history and features of the architectural and urban planning evolution of hospital systems, as well as the evolution peculiarities of hospitals as a complex urban planning subsystem within the multilevel system of the urban environment, were discussed. Hospitals gradually changed, transformed under the influence of various external and internal factors, public demands, needs and expectations from healthcare. Reforming the hospital system is an extremely actual, complex and difficult process for any country. Hospital design trends: the enlargement of medical buildings, the formation of complexes; emphasis on the intensity of treatment, the use of day hospitals; individualization of design decisions, rejection of stereotypical hospital forms; the formation of an aesthetic space with healing potential; ecological approach and harmony with the environment.
\end{abstract}

Keywords Dynamics of Development, Architectural and Urban Planning Analysis, Hospital, Healthcare, Regularity of Development, Medical Institutions

\section{Introduction}

The term "hospital" (from lat. Hospes - stranger, foreigner, guest) - medical and preventive institution that provides the population with inpatient medical care, and in the case of combination with a clinic and outpatient care [1]. Derived from English. hospitality can be translated as "hospitable". In German - spital, as well as krankenhaus - is a home for the afflicted. Today, there are several definitions of the term "hospital". According to one of them, the hospital is "an institution providing beds, meals and constant medical care for its patients while they are being treated by professional doctors" [2]. It is worth noting that this definition is too broad and affects the functions of other structures of the health system. The architectural expression of space-planning decisions of hospitals in the world is very diverse. At the same time, hospitals include obsolete compact buildings with a small amount of stationary support, and large multidisciplinary complexes equipped with advanced equipment (Fig. 1, Fig. 2).

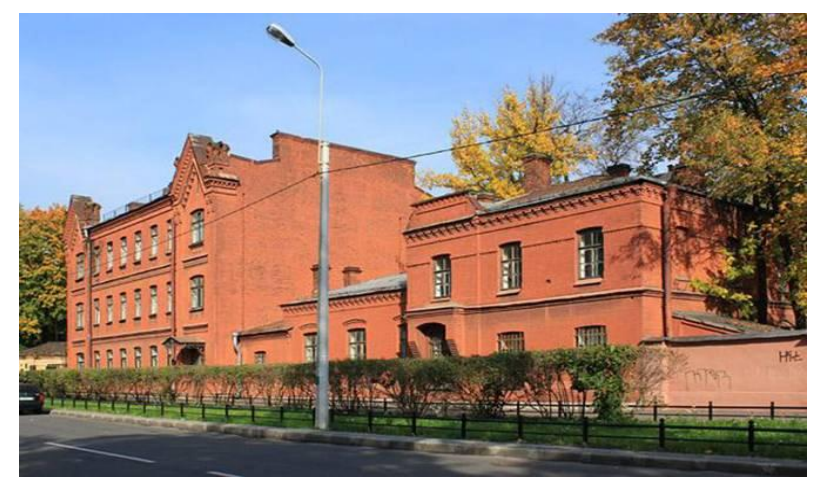

Figure 1. Children's City Infectious Diseases Hospital № 3. St. Petersburg 
The resulting diversity is associated with the amount of funding allocated in various countries for health care. Typological classification of hospitals, quite diverse in different countries of the world, can cause certain difficulties and ambiguity. For example, hospitals include medical facilities with a small volume of emergency treatment combined with an extensive long-term care service; public hospitals providing medical care; nursing homes with the presence of medical personnel [3]. A hospital can be located in one building, occupy several buildings simultaneously in one territory or in a group of buildings located in different places, which are combined into a single organizational structure.

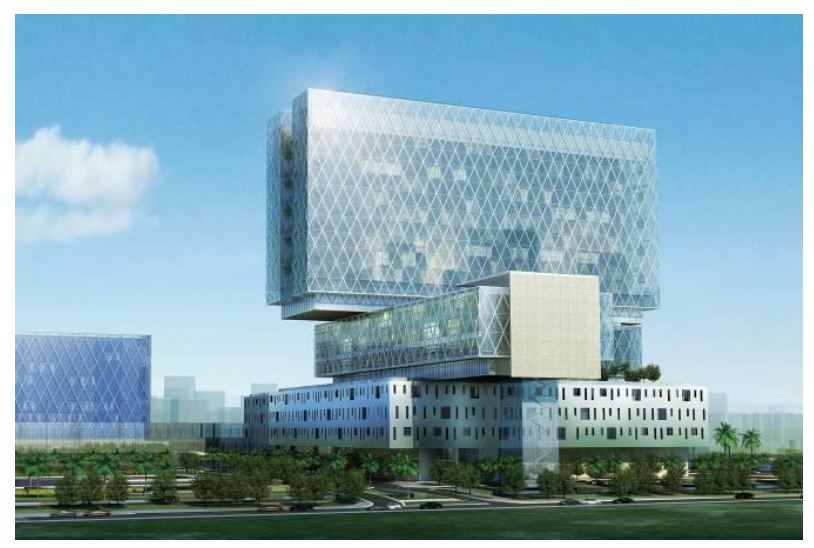

Figure 2. Clinic Abu Dhabi's Cleveland. Abu Dhabi

An example of the latter is the experience of Great Britain, in which since 1992 the concept of "hospital" has been practically not used, and instead the concept of "hospital trust" (hospital buildings located in different places) is widespread (Fig. 3) [4].

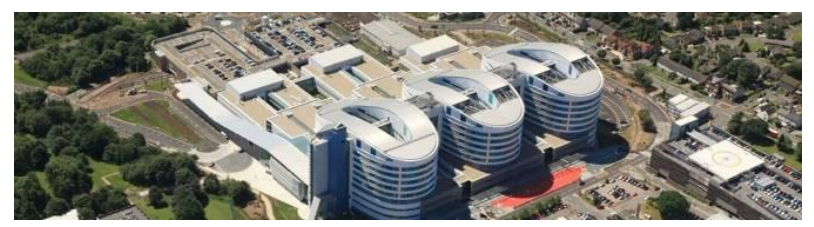

Figure 3. University Hospitals Birmingham NHS Foundation Trust. Birmingham

At the same time, in other countries, the "dispersed" buildings of one hospital in different territories, but functioning as a single organization, have a certain autonomy. Thus, the existing diversity of understanding of the essence, function and organization of hospitals requires an attempt to systematize and generalize information from the formation of the first hospital buildings to modern volumetric-spatial and architectural-planning decisions of hospitals.

The peculiarity of the modern stage of the evolution of hospitals lies in the wide range of medical services outside the physical walls of the medical building, the concept of "hospital without walls" or "hospital at home" has appeared. Hospital services in developed countries extended to the provision of rehabilitation measures at home; innovations in the field of short-term painkillers allow small autonomous surgical units to perform operations on an outpatient basis; autonomous maternity units, mobile units for chronic patients are functioning. Thus, the term "hospital" in different countries has different meanings and functions. Most Western European hospitals focus on the management of acute cases, while hospitals in Eastern and Southern Europe continue to serve as social welfare and health care providers. Hospitals are an indicator and an important element of the healthcare system throughout the civilized world. The high importance of hospitals in the healthcare system is due to several reasons: firstly, funding for hospitals occupies a significant part of the healthcare budget (up to $50 \%$ in Western European countries and more than $70 \%$ in the post-Soviet space); secondly, hospitals provide access to specialized medical services; thirdly, the experienced staff of hospitals forms the main fund of medical professionals. It should be noted that in recent years, thanks to the active progress of medical technologies, the increasing importance and introduction of evidence-based medicine, hospitals have become an innovative training ground and an important factor affecting the health of the population as a whole (Fig. 4) $[5,6]$.

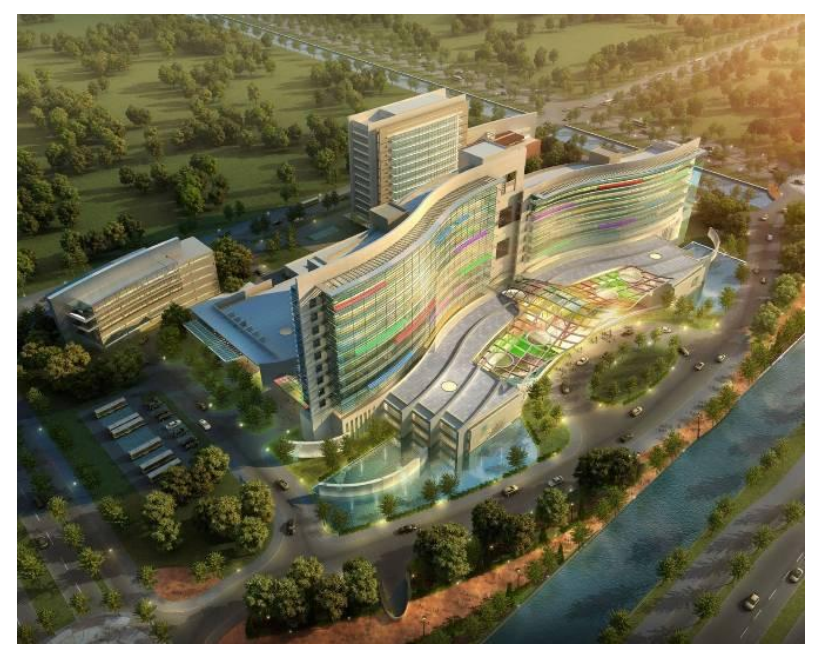

Figure 4. Children's Hospital in China. Suzhou

The effective functioning of hospitals is influenced by numerous factors, including changes in the number and composition of the population, the prevailing picture of morbidity, the emergence of new opportunities for medical intervention (diagnosis, treatment and rehabilitation) associated with the development of scientific and technological progress. Of course, new forms and possibilities of treatment often require new hospital buildings or premises, as well as training of medical personnel in new methods of work. Separately, it is necessary to note the traditional distinction between hospital treatment and the provision of primary medical care to the population: with the significant potential of 
professionals, equipment and laboratories, round-the-clock operation, the hospital is able to provide short-term consultative and diagnostic assistance to the population in cases of self-treatment after hours, significantly reducing the burden emergency and emergency medical services (Fig. 5).

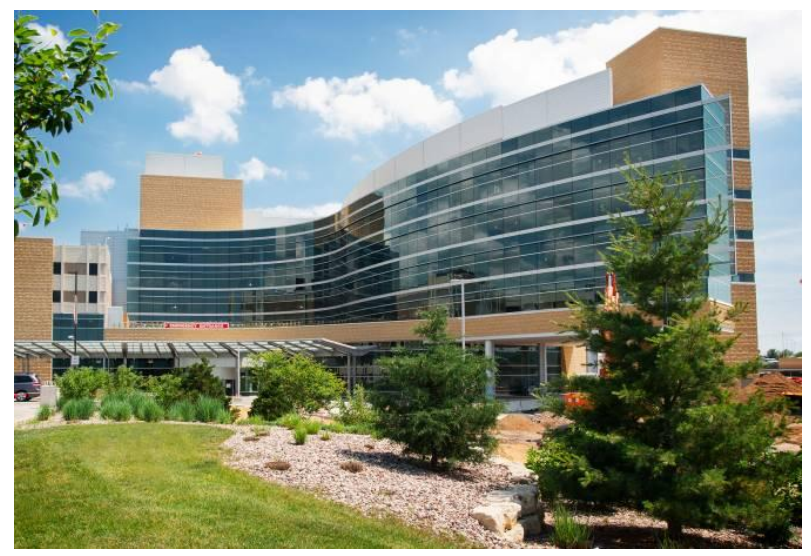

Figure 5. Gundersen La Crosse Clinic. La Crosse

One of the leading manifestations of the evolution of hospitals at the present stage of development can be called the desire of most leading countries that began in the 1980s to reduce the capacity (or throughput) of hospitals, while focusing on alternative forms of organizing medical care [7-11]. Starting from the indicated time, hospitals gradually began to strive to limit their activities to treatment of acute cases, providing intensive care, as well as making complex diagnoses or conducting complex treatment. Taking into account the leading world experience, domestic hospitals should also strive for optimization in order to increase their own efficiency, spending the allocated funding not on the formal implementation of the inpatient treatment plan, but on its performance indicators [12, 13]. When considering the world experience in the design, construction and operation of hospitals, it is certainly necessary to take into account the subregional differences of countries - the health system of each individual country captures its culture, traditions, history, political and economic orientation (Fig. 6) $[14]$.

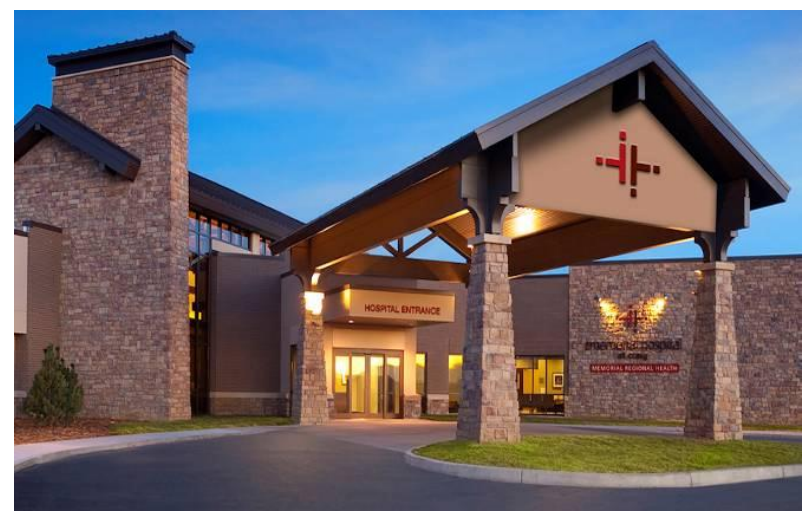

Figure 6. Colorado Craig Memorial Hospital. Colorado, Craig
It must be taken into account that the policy of a healthcare organization, effective in one cultural and historical context, can only be critically adapted to be transferred to other soil.

\section{Materials and Methods}

The research is mainly composed of a systematic and comprehensive analysis of the medical network and hospital complexes of the leading countries all over the world. An analysis of literature, normative, information sources, graph-analytical methods, photo-graphic fixation, and field examination were used in the study [39-42].

The scientific and methodological basis for the research are fundamental works in the field of history of architecture and urban planning: A. Ikonnikov, S. Khan-Magomedov, O. Orelska, I. Vysochyn, M. Votinov. Theoretical and practical issues of urban planning systems analysis were considered in the research of $\mathrm{K}$. Linch, A. Gutnov, V. Glazychev; using system analysis in architectural and urban planning systems of Y. Surmin, G. Lavryk, V. Timokhin. Architectural typology and planning of medical institutions were investigated: R. Allen, J. Bishop, P. Blandella, T. Bulychova, T. Zyuzina-Zinchenko, K. Pidgirnyak. Foreign experience of architectural and spatial organization of medical institutions is covered in the works of architects: $\mathrm{Ch}$. Schirmer, Ph. Meuser, H. Nikl, H. Nicki-Weller. The main focus of the researchers was on solving the theoretical issues of forming the architecture of medical institutions or the organization of the architectural environment of medical institutions of a certain professional area, while at the same time, the study of the dynamics of architectural and urban development of the system of treatment complexes was undisclosed.

\section{Optimization of Hospital Capacity}

One of the traditional indicators of the functioning of hospitals is the number of patients served, measured by the number of hospital capacity. Today there is an active discussion about the "correct" value of this indicator. The opinion was confirmed that in the Soviet period the capacity of hospitals in Eastern Europe was excessively high and in the current economic realities, a significant optimization of the estimated number of inpatient patient care is required. However, if a comparison is made with Western European norms of capacity, then it is necessary to take into account existing regional features, for example, the level of the social security system of the population. It is also necessary to take into account the negative consequences of an excessive reduction in the capacity of hospitals, as happened in the UK and the USA: the reduction in the number of staff and the reduction in the provision of medical services occurred without a 
corresponding adjustment of the volume of work and workload. As a result, increasing pressure on medical personnel led to a deterioration in the quality and effectiveness of treatment, as well as to the need for long waiting in line for medical services [15].

Turning to specific figures, it can be noted that since the 1980s, the numerical indicator of places in hospitals across all European countries began to decline. Today it can be observed that in the EU countries, a decrease in the generalized number of hospital inpatient beds occurred from 600 to 450 per 100 thousand of the population; in the post-Soviet countries this indicator decreased from 1000 to 760 , in the countries of Central and Eastern Europe from 700 to 640 per 100 thousand of the population. If this indicator is considered for individual countries, then there are significant differences. For example, in all EU countries the number of hospital places per 100 thousand population decreased, although the initial (before the start of reduction) level for individual countries varied significantly: in Germany - 840, in Italy - 780, in France 620 , in Sweden - 500 and in the UK - 300. We see that Germany's figure is about twice as high as the EU average, despite a further decline, while in Italy it is still twice as high as in the UK -16 .

No less important and responsible questions is determining the objective need for the number of places in hospitals and whether optimizing the capacity of hospitals will actually lead to the desired cost savings - ignoring or incorrect preliminary analysis of these aspects of the reorganization of the quantitative potential of hospitals can lead to an increase in the intensity of operation of other medical institutions [9]. The use of the term "inpatient place" (or "hospital bed") as a way of calculating the capacity and productivity of a hospital's work is rather arbitrary and may vary significantly in different countries. When measuring the effectiveness of a hospital, it is necessary to take into account: whether all stationary places fall under this concept, regardless of whether they are used or not; a regular bed can be understood as one of twenty, served by one nurse, as well as an individual unit of intensive care. Thus, this indicator is an inaccurate term that designates and assumes a number of related concepts, including nurses, support staff, modern equipment, etc. Another equally common indicator, such as the average length of stay in the hospital, can also have different interpretations depending on the procedure for admitting a patient. For example, if a patient is hospitalized late in the evening, then the average length of stay in the hospital rises.

\section{Hospital Study}

Despite the enormous role of hospitals in the field of healthcare, their activity, organization, and functioning features have not been sufficiently studied [17]. The reason is that the few scientific papers devoted to the activities of hospitals are rarely widely known; positive and negative innovations, despite the experience of restructuring hospital systems, remains insufficiently stated and analyzed [18, 19]. It is worth noting that a low study of the functioning and features of the organization of the health care system, including in terms of architectural and urban planning aspects, is in sharp contrast with the abundance of scientific work on all kinds of forms of medical progress. That is, the invention of a new medicine necessarily passes the testing procedure and cannot be implemented without comprehensive scientific experiments. As for the search for new architectural and urban forms of spatial organization and the provision of therapeutic measures, their implementation occurs without proper scientific assessment. New architectural and urban transformations of the healthcare system, as a rule, are developed under the influence of economic and political imperatives, but their impact on patients and medical personnel rarely becomes the subject of research attention. Meanwhile, it can be assumed that there is a correlation between the level of treatment effectiveness, morbidity and mortality with the architectural and urban planning environment of the medical building, in which medical services $[20,21,22]$ are produced and provided. Thus, the question of the influence of the architectural environment of hospitals on the state of health, the healing properties of the internal and external space of a medical building, its surrounding territory is not sufficiently studied. It is worth recognizing that this task is truly complex and ambitious. A modern hospital is a complex multifaceted and multifunctional interactive system (Fig. 7).

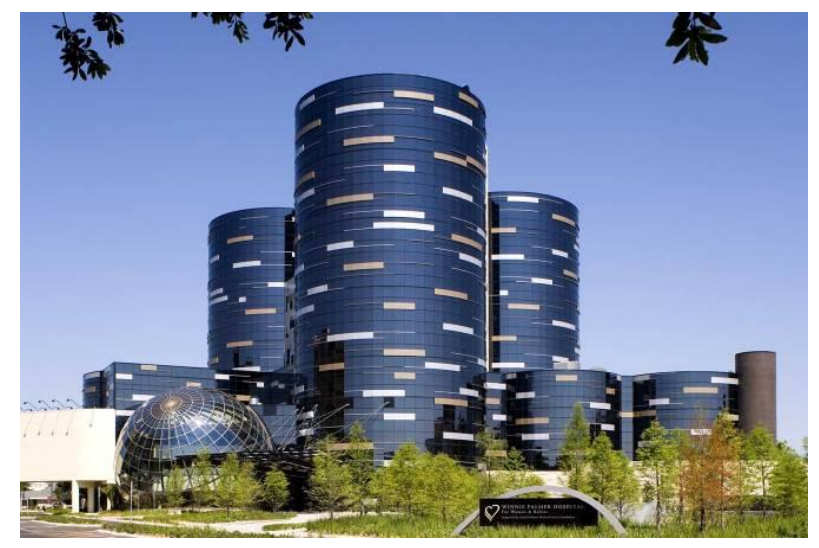

Figure 7. Orlando Health Winnie Palmer Hospital for Women and Babies. Florida

The tasks facing large hospitals and hospital complexes, multi-vector and diverse, often conflicting with each other $[23,24]$ and significantly differ from the tasks that are put forward before the design of individual units (intensive care units, diagnostic laboratories, etc.) The hospital unites many functional groups, each of which is characterized by its own needs, limitations and conditions. A comprehensive assessment of the complex organization of the hospital system cannot be carried out within the 
framework of a focused, "reduction" research procedure, which is possibly acceptable when evaluating the effects of a new medication or artificial organ. It must be admitted that the empirical basis for studying the architecture of hospital systems is complicated and unequal: for some indicators it can be quite reliable, for other criteria it must be recognized as unsteady, but in most cases it all depends on the context.

\section{Hospital Reforming}

Transformations of complex hospital systems are associated with overcoming serious difficulties and obstacles. The structural inflexibility of hospital buildings and the intensive pace of their use contrast with active innovative processes in the field of medical technology, engineering and equipment, means and methods of treatment. Hospitals are usually characterized by significant sustainability, which is based not only on the structural organization, but also on the cultural, regional context (Fig. 8).

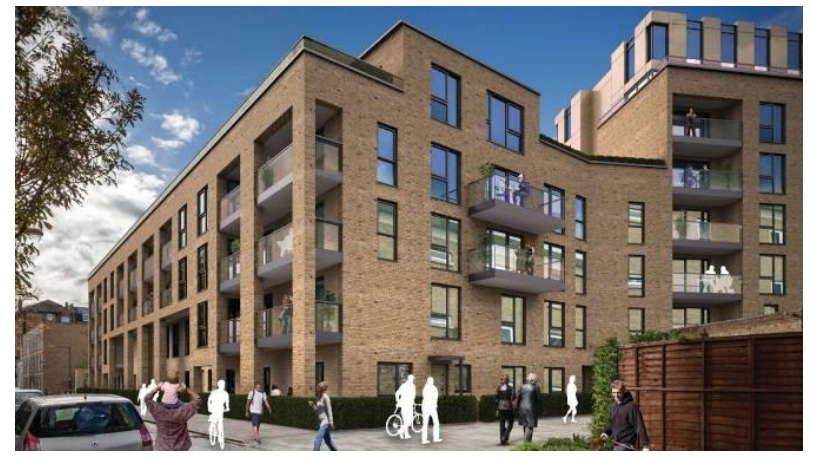

Figure 8. Reconstruction of The Queen Elizabeth Children's Hospital. London

A significant time of the existence of hospitals, their buildings were designed as structures under meant for long-term and constant use. The configuration of hospitals today, unfortunately, reflects outdated health care practices and does not take into account the dynamics in the structure and nature of the prevailing incidence. For example, in Western Europe there are hospitals that have historically been located in the adapted premises of former monasteries and have only recently received the status of museum complexes (Fig. 9, Fig. 10). It is worth noting that even relatively new hospitals are not able to match the dynamic processes of the development of medicine. The inability and mismatch of such hospitals can manifest itself starting from an insufficient number of electrical outlets for an increasing number of electronic devices, ending with an insufficient number of operating places, outpatient care departments, etc. The culture, or rather ethics, of hospital services must also adapt to changing socio-economic circumstances. and population expectations. Leading hospitals are thought of as "palaces of medical power" or "places of hope for healing". Prestigious hospitals, which involve the professional medical elite, are more resistant to optimization and can effectively counteract attempts to reduce hospital care.

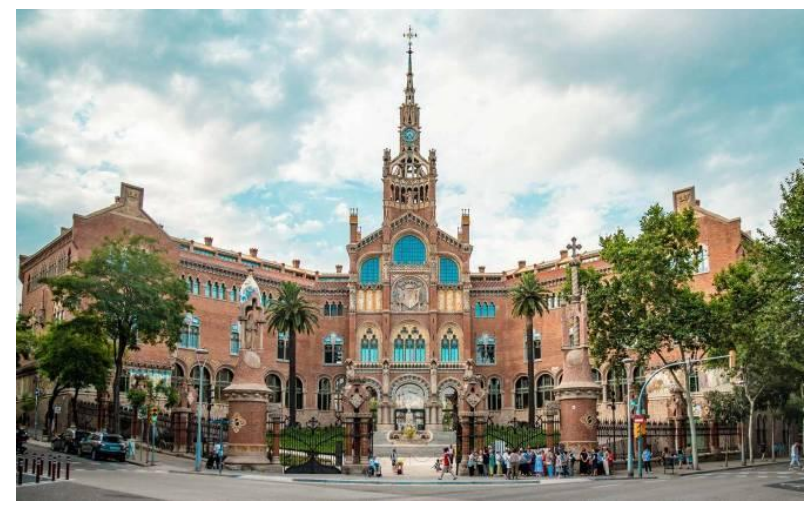

Figure 9. Hospital de Sant Pau. Barcelona

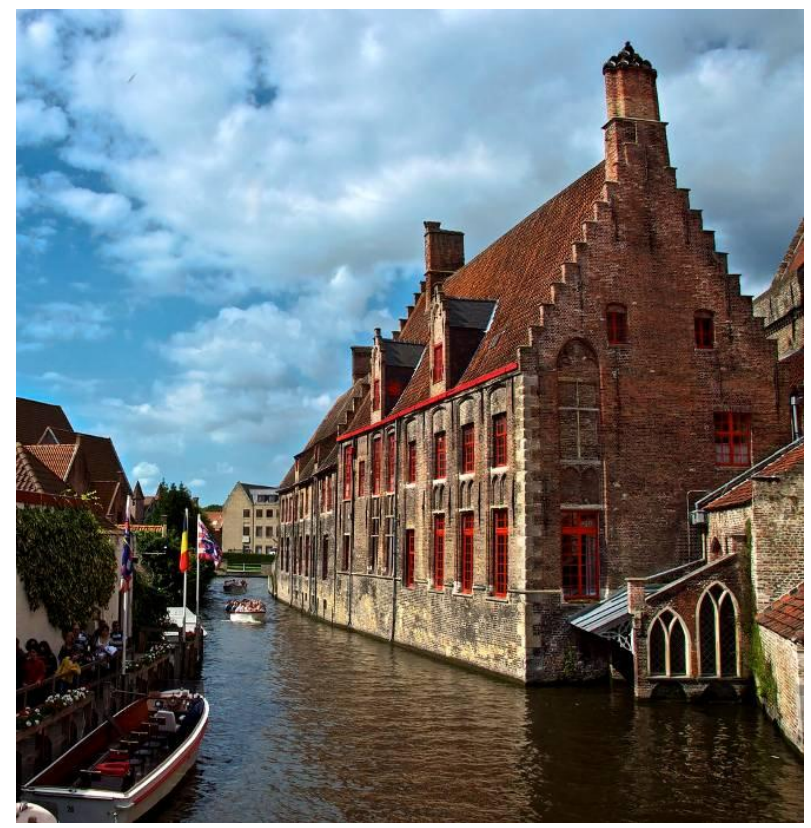

Figure 10. Old St. John's Hospital. Brugg

\section{Reasons for Hospital Reform}

The experience of health care reform in Europe has led to several useful conclusions. The introduction of the foundations of market relations based on competition, containment and regulation of the budget proved to be quite effective $[8,25]$. Positive measures aimed at improving the work of hospitals should also include the establishment of restrictions on the hospital budget and regulation of the distribution of the hospital. The analysis of factors affecting the health of the population and, as a result, the functioning of hospitals made it possible to identify the main ones: changes in the age composition of the population (aging of the nation), changes in the structure of the morbidity of the population, and rapid 
technological progress. Of particular importance are studies on the optimal configuration of hospitals, as well as the impact on the professional behavior of hospital staff.

\section{A Systematic Approach to Hospitals}

To solve the problem of reforming the hospital system, it is necessary to approach the issue from a systemic point of view. The concepts and principles of system theory, which are actively used in various scientific fields, are today reflected in the study of such complex organizations as [26] hospitals. The arsenal of the general theory of systems offers a number of universal concepts that help to explain from a scientific point of view the nature and patterns of the hospital, to identify and organize existing problems. The key property of any open system is that it must interact with the environment, provide and replenish the missing resources necessary for its existence, adaptation and progressive growth (Fig. 11) [27].

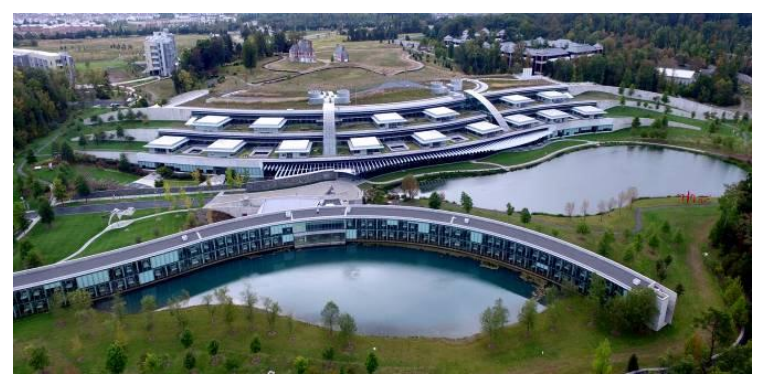

Figure 11. Howard Hughes medical institute. Virginia

In this aspect, a hospital can be considered in the context of its own environment, which should be an important focus of research interest. The hospital may respond to reorganization measures and incentives taken, depending on its formulated new role and function, as well as on the beliefs and experience of those who interact with it. In this context, it will be useful to turn to an analysis of the historical development of hospitals in European healthcare systems. An important property of a hospital system is that it exists within the hierarchy of other systems; accordingly, the hospital can be examined in terms of different system levels. A single hospital should be considered as part of a holistic urban planning system of hospitals, as part of the healthcare system of a particular state, and, finally, as part of a large socio-economic and political system.

The next fundamental concept of systems theory is the interdependence between the various elements that make up a single organizational structure. The source of systematicity is to ensure the totality of organizing interactions between individual components and parts; the properties of individual parts can be interpreted only in the context of the whole. The hospital is a comprehensive organization consisting of a number of subsystems. The latter include, for example, personnel recruitment and retention systems, support services organization systems, diagnostic clinical program support systems, etc. The system can be imagined as a set of organized interactions [26]; the characteristics of each individual system are determined by the configuration of its components and the relationships between them. Further, in the theory of systems, the concept of self-regulation is used: the organization maintains relative stability due to the action of homeostatic mechanisms involving the presence of information feedback. Despite the fact that the concept of a self-regulating system has a biological origin, it contributes to an understanding of the reasons why hospitals are opposed to radical changes and the lack of ability of medical institutions to independently modify their organization in a qualitatively new type. Elements of the system, including individual hospitals, are in dynamic interaction with each other, as well as with an updated environment. These relationships directly affect the optimal size of each component and the way elements are distributed. In the context of a systematic approach to the study of the organization of hospital facilities, the above statement can be interpreted as a search for the optimal scale of hospitals, the distribution of the planned load and, as a result, the predicted performance.

\section{The History of the Formation of Hospitals}

Hospitals, as objects of architectural and urban planning, have a rich centuries-old history. Over the course of evolution, for centuries hospitals have performed various roles and functions, their architectural space-planning decisions have come a long way from the initial use of adapted rooms, later the pavilion placement in special buildings, decentralized, block, centralized and, finally, mixed typological organization. In the Middle Ages, hospitals served as a haven for the poor at monasteries, in the XVIII century were the last refuge for the dying, and since the twentieth century gradually acquired the status of a symbol and embodiment of the possibilities of the modern level of healthcare development. Of course, the design and organization of modern hospitals reflect both current needs and the cultural heritage of the past. Moreover, due to the rapid and progressive impulse of the development of science and technology over the past two centuries, an ordinary modern hospital in civilized countries today is absolutely not like a hospital fifty years ago. The main trend in the evolution of hospitals today can be called a decrease in the number of places provided for the treatment of acute cases, an increase in throughput due to a reduction in the length of hospital stay, and an increase in the hospital utilization rate. Over the centuries, the evolution of hospitals has been dependent on social and political changes, on the progress of medical science (Table 1). 
Table 1. Historical evolution of hospitals

\begin{tabular}{|c|c|c|}
\hline Hospital role & Period of time & Characteristics \\
\hline Treatment. & VII cent. & Byzantine, Greek, and Arabic doctrines of disease. \\
\hline Care, spiritual care. & X-XVII cent. & Hospitals affiliated with religious organizations. \\
\hline Contagious isolation of sick people & XI cent. & Caring for infectious patients (lepers, etc.). \\
\hline Treatment of the poor. & XVII cent. & Philanthropic and state institutions. \\
\hline Healthcare. & End of XIX cent. & Medical care and surgery; high mortality rate. \\
\hline Surgical Centers. & Start of XX cent. & $\begin{array}{l}\text { Technological transformation of hospitals; the emergence } \\
\text { of patients from the middle class; expansion of outpatient } \\
\text { departments. }\end{array}$ \\
\hline Health systems centered around hospitals. & 1950-th years. & Large hospitals, "temples of healing and technology". \\
\hline General Hospital District. & 1970-th years & $\begin{array}{l}\text { The emergence of district general hospitals; local, } \\
\text { secondary and tertiary hospitals }\end{array}$ \\
\hline Hospital for acute cases. & 1990-th years. & Active treatment for a short time \\
\hline Outpatient Surgery Centers. & 1990-th years. & Reception of patients no more than a day; sparing surgery. \\
\hline
\end{tabular}

According to some sources, one of the first hospitals appeared in Byzantium in the period of the VII century. (Fig. 12) [1]. By the XII century small hospitals were already functioning in many Arab cities, and in 1283 a large hospital was built in Cairo (Fig. 13) [28]. The idea of constructing a special building designed to treat the sick and wounded arose in the Christian territories as a result of the 11th century crusades. Over the next several centuries, the Knights of St. John and the Knights Templar built hospitals throughout Europe [28].

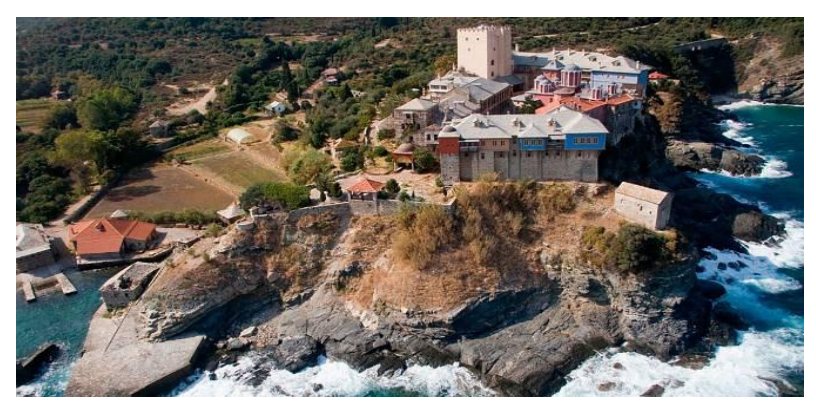

Figure 12. Monastery of Pantokrator. Constantinople

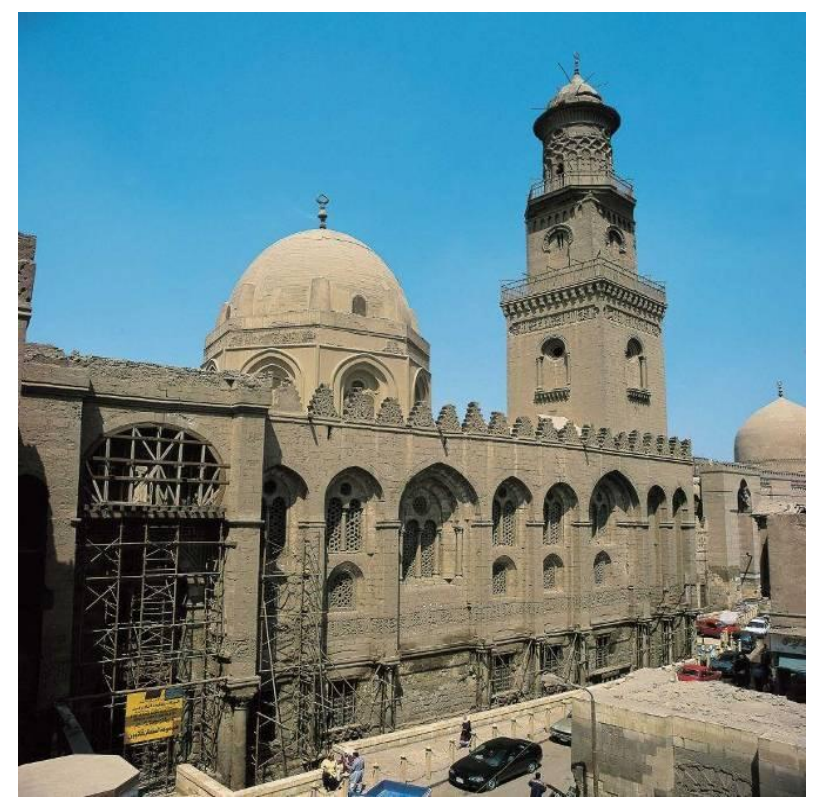

Figure 13. Hospital at Qalawun complex. Cairo 
Until the XII century predominantly small hospitals were built that provided treatment, shelter for the sick and poor, isolation of people with infectious diseases [28].

The creation of many early hospitals was motivated by the Christian ideal of healing the sick and alms to the needy; philanthropists supported hospitals, thus showing their mercy, sometimes seeking to atone for sins or to demonstrate their wealth and social position.

Medieval hospitals were often built at monasteries. In 1123, the St. Bartholomew (Fig. 14), in 1231 the Hotel-Dieu hospital was built in Paris (Fig. 15), and in 1288 the Santa-Maria-Nuova hospital (Fig. 16) [28] appeared in Florence. Significant changes in the construction of European hospitals have occurred since the 13th - 16th centuries, when the activities of hospitals acquired a pronounced medical focus [28, 29].

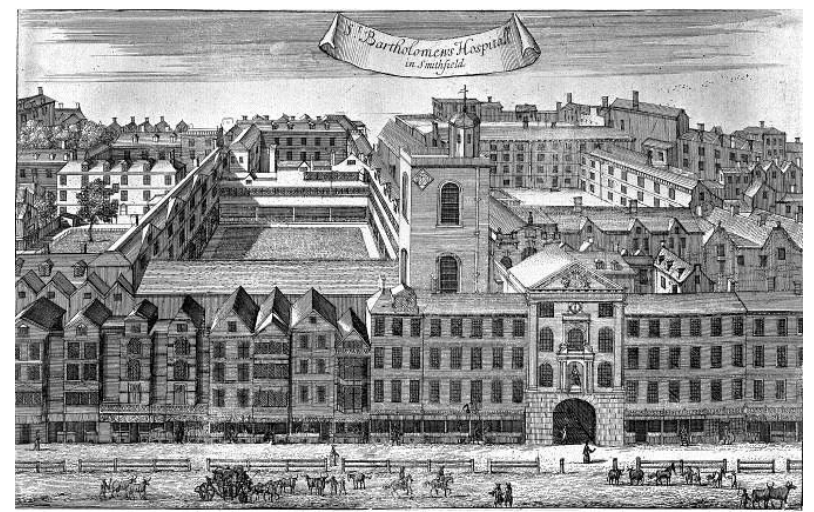

Figure 14. Bartholomew's Hospital. London

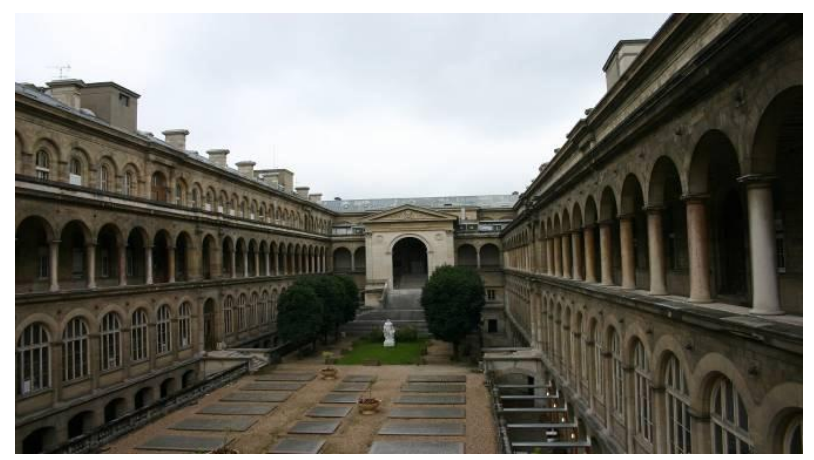

Figure 15. Hôtel Dieu. Paris

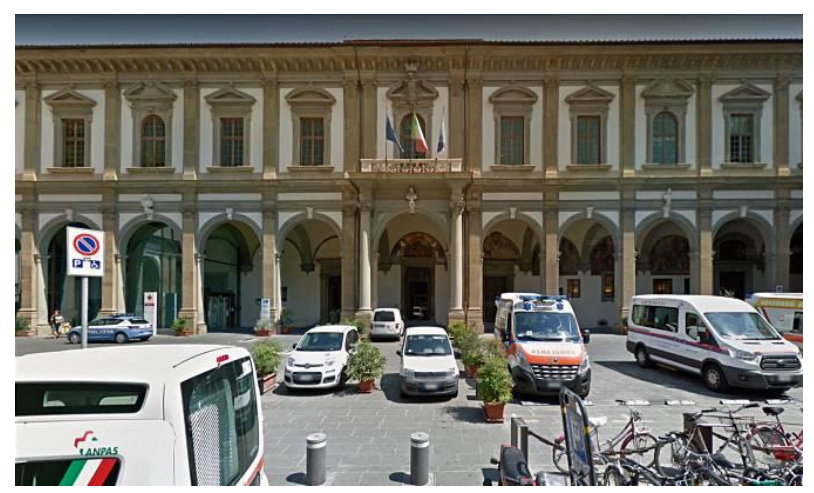

Figure 16. Ospedale di Santa Maria Nuova. Florence
The growth of urbanization in the XVII century influenced the emergence of such institutions as the Paris-based La Pitier-Salpetriere hospital, which can rightfully serve as an illustration of the transition of hospital-shelters to the prototype of modern hospital organizations (Fig. 17) [30, 31]. The political events following the French Revolution of 1789-1794 accelerated the process of separation of hospitals from the patronage and guardianship of the church. During this period, free non-church hospitals funded by private donors appeared; actively developed new forms of treatment; in hospitals, a distinction was made between "treatable" and "incurable" patients.

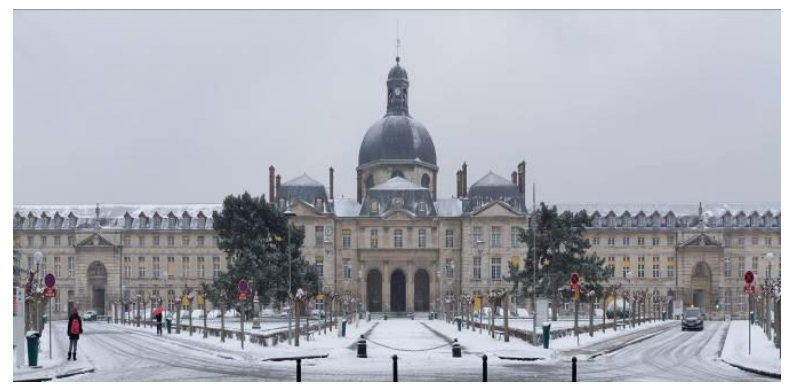

Figure 17. Pitié-Salpêtrière Hospital. Paris

Since the XIX century the state began to take part in caring for the poor and sick in rapidly growing European cities. It is worth noting that a significant part of modern Western European hospitals owes their origin to this evolutionary round of healthcare development and was built during this period as charitable medical institutions for the poor. A wealthy and rich population of European countries preferred to receive medical care at home or in small private hospitals. Over time, admission to the hospital began to be determined not by social, but by medical criteria; decisions about hospitalization began to be made not by philanthropists, but by doctors. By the end of the XIX century. public and private general hospitals functioned in all major European cities. Training and research was carried out mainly in public hospitals; Clinicians worked in municipal hospitals, usually a few hours a week [32].

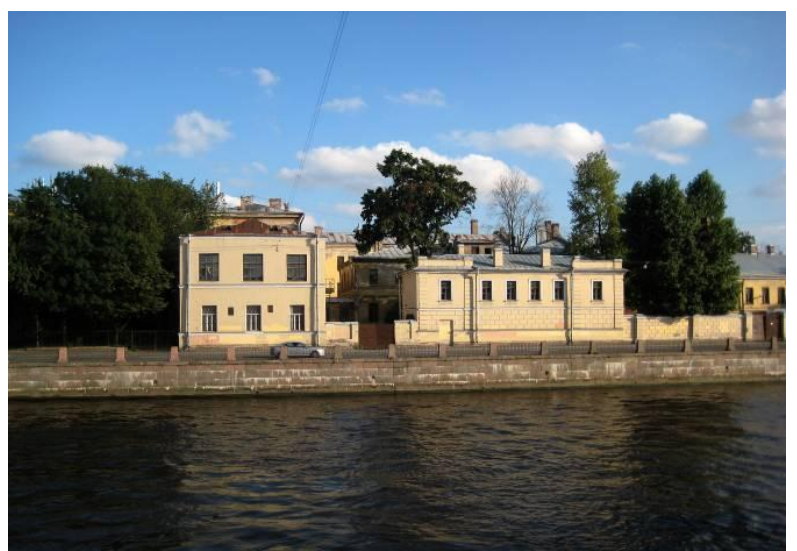

Figure 18. Alexander Hospital. St. Petersburg 
As the role of hospitals in the development and strengthening of health care increased, they more and more needed state support and guardianship. In the twentieth century most European hospitals came under state control: contributions from philanthropists and patients could no longer cover the rising costs of treatment. The rapid evolution of hospitals from the end of the XIX century largely due to the development of aseptic and antiseptic methods, anesthesia and surgery, the general revolution in science and technology [33].

The nature and role of the hospital as a medical institution has radically changed. The prevalence of infectious diseases in hospitals, especially in the surgical and maternity wards, has fallen sharply. The degree of complexity of surgical operations has increased, as has the proportion of recovering patients. At the end of the XIX century. hospitals began to diagnose and treat patients on an outpatient basis; outpatient treatment gradually took a significant place in the activities of hospitals (Fig. 18).

Serving the middle classes, European hospitals were forced to develop and show responsiveness and cordiality to visitors, which later became the basis for the formation of a competitive business experience and commercial approach. In the second half of the XIX century. The specialization of medicine sharply increased and specialized hospitals first appeared. During this period, some professional groups of doctors and hospitals "focused on certain parts of the body, others on diseases, still others on life events, fourth on age groups" [28, p. 38]. By the beginning of the twentieth century there was a significant fragmentation of medicine into separate specialties: "new hospital departments and research centers" [28, p. 388].

A significant breakthrough in medical research allowed by the end of the XIX century to understand the nature of infectious diseases, the professional basis of nursing has been formed. In the first decades of the twentieth century hospitals began to play in society the role that they retain to this day. As the scope for clinical intervention has expanded, medical technology has become increasingly complex and costly. Hospitals began to provide not only medical care, but also full treatment.

The peculiarity of the $1950 \mathrm{~s}$ is that the significant activation and development of modern medicine has moved to hospitals at higher educational institutions. Hospitals have become "a large launching pad for the medical elite, automated factories for medical production lines" [28, p. 647]. Thus, hospitals are conditionally divided into two classes. Some hospitals (university), located in the centers of large cities, have developed into large multidisciplinary medical institutions equipped with sophisticated equipment and meeting the level of recent requirements. Other, less "advanced" hospitals included a significantly smaller range of medical specialties and functioned as district hospitals for suburbs, large cities or the [34] countryside.

However, in the 1970s, the use of advanced technologies, active research and training, the availability of doctors of various specialties spread and strengthened in most district hospitals, and not only in clinical ones, which in turn led to leveling the line between hospitals. The most significant changes have occurred since the 1950-1970s due to the progress of laboratory diagnostics, as well as the widespread construction of hospitals in an industrial way and according to standard designs.

This design and construction approach, of course, made it possible to cover the maximum number of people with medical care, but from an aesthetic point of view, hospital buildings, devoid of individuality, "decoration and decorative refinements" began to look like faceless concrete "boxes" with "cell-wards". The hospital has turned into a functional "machine" designed for conveyor bodily (physical) treatment of the flow of an "impersonal" population (Fig. 19).

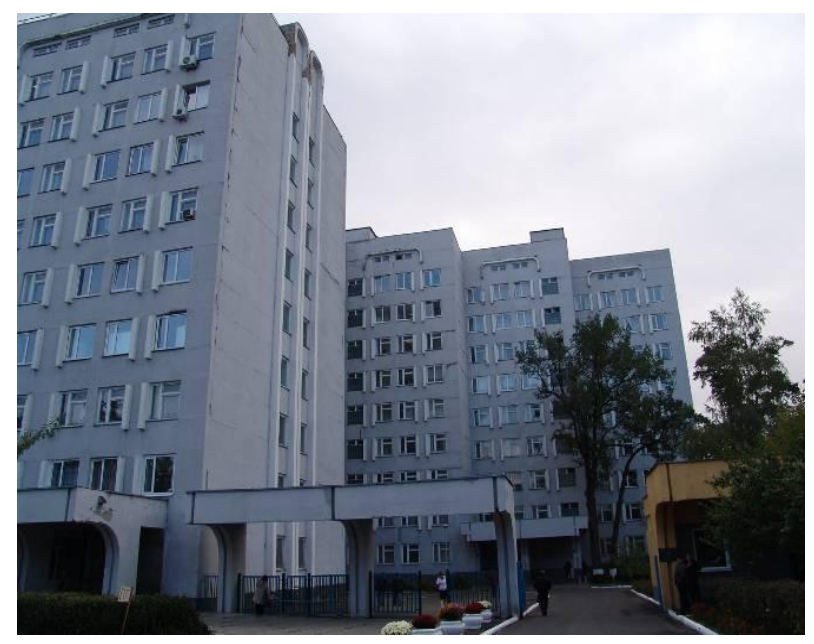

Figure 19. Kyiv City Clinical Oncological Center. Kyiv

\section{Trends Characterizing the Design of Modern Hospitals}

When approaching the issue of advanced trends in architectural and urban planning [35-37] and the organization of hospitals, it is necessary to take into account that the possibilities to correctly compare the experience of organizing hospital systems in different countries are quite limited. This statement is based on a combination of aspects, but first of all, the complexity of the study is hindered by a variety of regional mechanisms and approaches to the organization and design of hospitals in various countries: from a system for calculating the measurement of capacity, quantity, access radius, efficiency of hospitals to a socio-economic role, focus and dominant function in the provision of medical care. Certain difficulties associated with the collection of accurate data are due to the fact that in some countries the statistics of the private medical sector, military hospitals, etc. [6] are not taken into account in statistics. 
Today in the countries of Central and Eastern Europe, preference is given to designing large hospitals and complexes (hospitals with 1000 beds or more are widespread), with an increase in the territorial and temporal radius of service to the population (Fig. 20, Fig. 21).

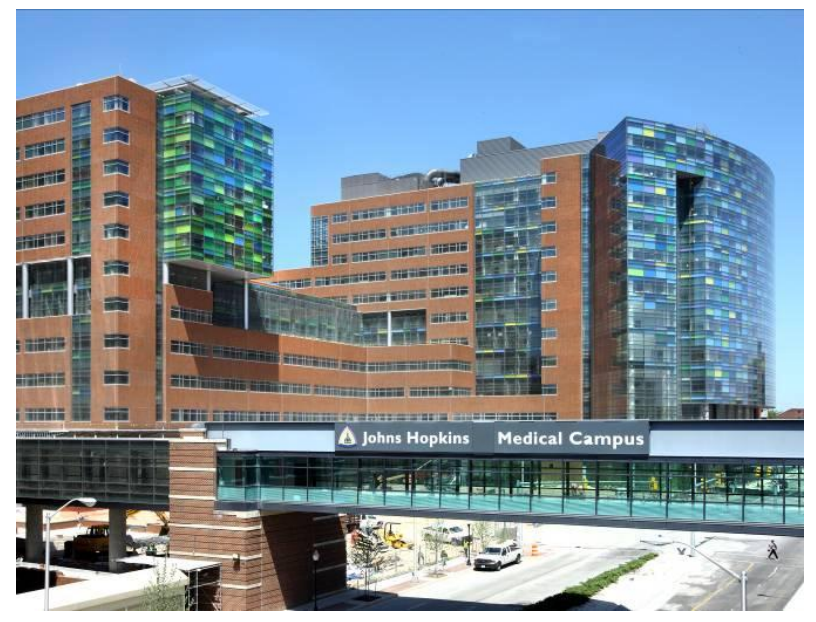

Figure 20. Johns Hopkins Hospital. Baltimore

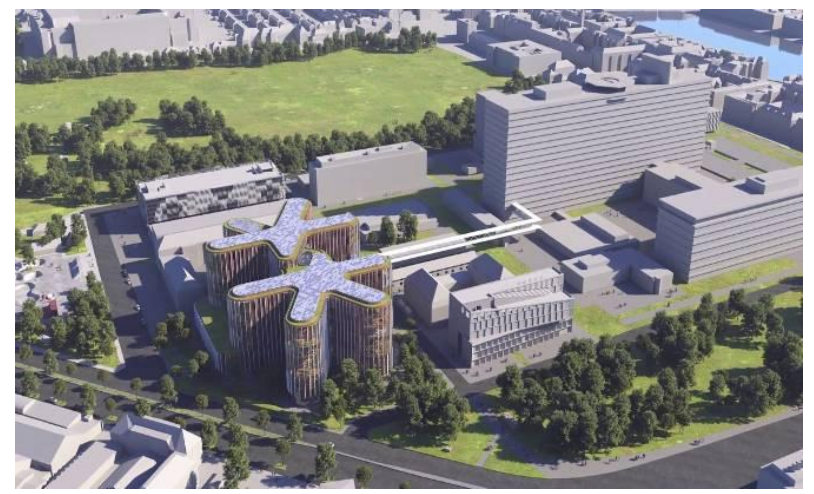

Figure 21. Children's Hospital. Copenhagen

This trend contributes to a decrease in the number of hospitals, since obsolete small and medium-sized medical institutions are simultaneously being closed. Since the 1990s, the trend towards a gradual decrease in the number of hospitals has also been observed in the post-Soviet space, however, in comparison with European countries, the variety and number of hospitals still remain much higher. A relatively common indicator of the capacity of hospitals, starting in 1980, the process of its reduction began in Western Europe, with an emphasis on the treatment of acute cases; in post-Soviet countries, the capacity of hospitals is approximately twice that of European [38].

Traditionally, when considering the effectiveness of hospital systems, take into account the indicator of temporary use of a stationary place. In most European countries, there is a tendency in the transfer of chronic patients who had previously been hospitalized for a long time to institutions of long-term social care or discharge home, with further care of the social assistance service. The length of stay in the hospital decreased markedly based on the distribution of medical recommendations for an early return to mobile life after surgery, the practice of a one-day hospital stay has spread. Of course, the tendency to reduce the length of hospital stay entails changes in patient care, in the use of medical and support staff. Health buildings today are mainly designed according to individual projects, which allow taking into account the complex of regional features of the area (climatic, urban, cultural, social, demographic, etc.) (Fig. 22, Fig. 23) [35-37, 39].

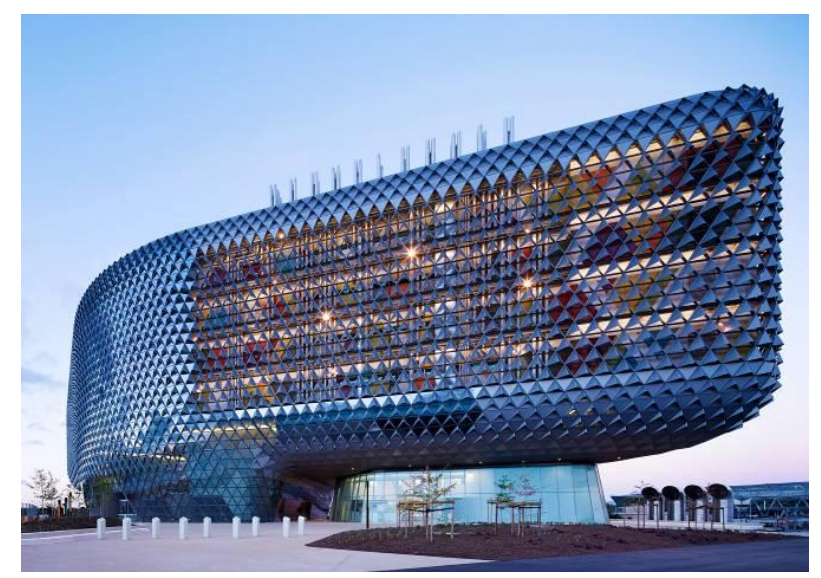

Figure 22. South Australian Research Institute of Health and Medicine. Adelaide, Australia

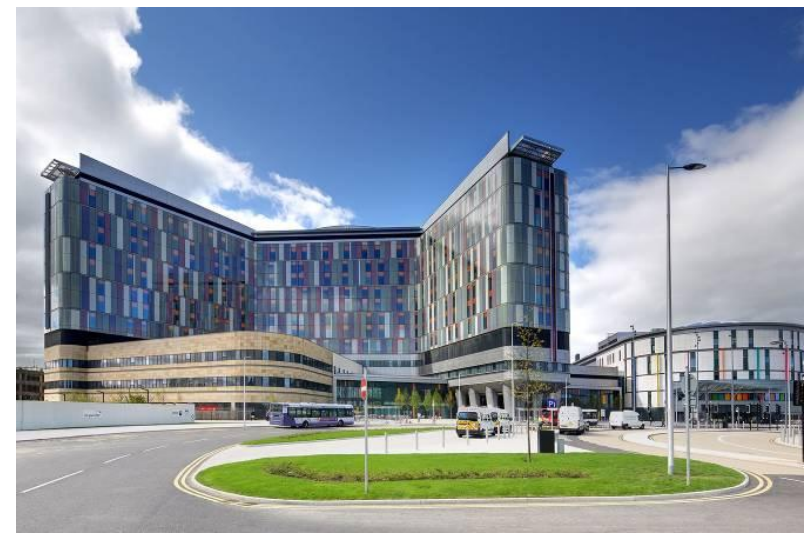

Figure 23. Queen Elizabeth University and the Royal Children's Hospital. Glasgow, United Kingdom

The abandonment of the typical design of hospitals also allowed architects to build medical buildings in a new architecture that can accumulate, shape and broadcast an environment that in itself has the potential of a healing nature. Staying in a hospital building, which embodies a modern and progressive approach to the design of external, internal space and landscaping, certainly contributes to the rapid healing process.

An integral component of the projects of the latest hospitals erected in economically developed countries is the introduction of environmental practices, the principles 
of sustainable architecture (Fig. 24) [35-37, 39-43]. This approach clearly illustrates that the hospital building is capable of being autonomous, resource and energy independent, harmonious in relation to the surrounding nature. This trend is one of the key, as it allows the construction of large medical buildings and complexes that allow saving on operating costs, which is relevant in the context of the energy crisis in most world countries.

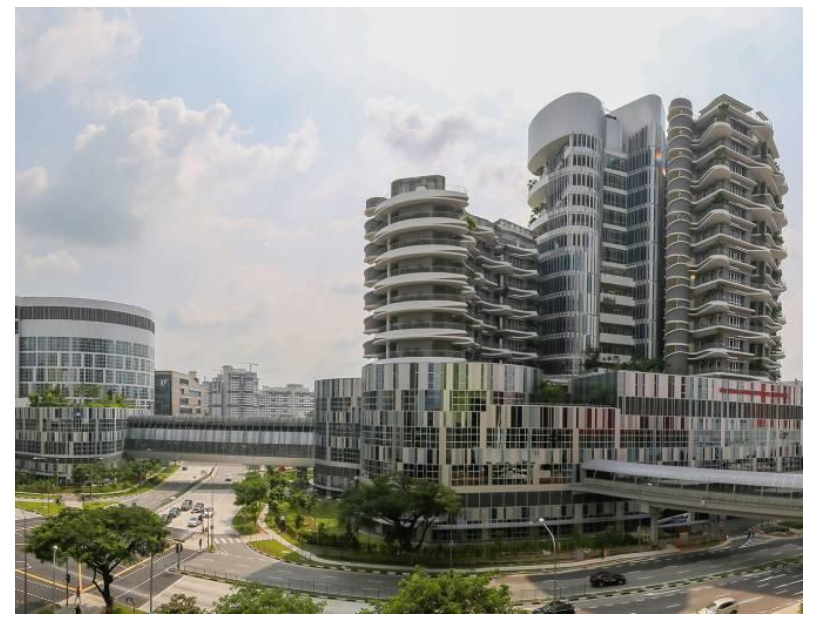

Figure 24. Hospital complex Ng Teng Fong General Hospital. Jurong, Singapore

\section{Conclusions}

The presented brief historical overview shows how hospitals gradually changed, transformed under the influence of various external and internal factors, public demands, needs and expectations from healthcare. The study outlines the historical evolution of hospital buildings, points out differences in the speed of evolutionary processes in different countries and regional contexts. It should be noted that reforming the hospital system is an extremely complex and difficult process (political, economic, etc.) for any country, including leaders in the economic sector. In the final part of the study, it is necessary to distinguish groups of the main problems associated with the design and reform of hospitals, which require further attention from scientists and practicing architects. When designing new hospital buildings and complexes, the main problems include: the need to create a project that initially provides different scenarios for further development (expansion of all or some of the constituent components, changing the functional purpose of certain components); the formation of multifunctional medical structures that allow you to combine different levels of medical care, as well as integrate related components - training, research and experimental processes; the relationship of the various components of the hospital structure with the minimization of corridors or (if this is not possible) the definition of additional functions for them. The main problems that need to be solved when designing a modern hospital also include finding ways for the sustainable development of the medical building, as well as the need to create an architecture that has the internal potential to generate a therapeutic environment. Thus, it can be argued that in the problematic field of designing new hospital structures, the need is synthesized for the combination of the classical "benefit, strength and beauty" with the complex concept of harmony (with man, with nature, with "genius loci", with the future, etc.). If we talk about the reconstruction of existing hospitals, then in addition to all the problems listed above, the main difficulty is added - in most hospital buildings built in the twentieth century, as a rule, there is no planning flexibility due to the use of wall structural systems, as well as a significant number of corridors that are designed exclusively for the function of horizontal communications between different treatment departments. The problem is also the dominance of the functional component in the projects of buildings in the medical field and the lack of attention to the need to address the aesthetic, psychological and spiritual comfort of patients and hospital staff. All these problems of designing and reconstructing hospital systems are generalized and, of course, can change in space and time. New tasks and difficulties may arise related to the increasing capabilities of the design and construction industry and, as a result, the expectation of such changes in the field of designing healthcare buildings.

The way out of this situation can be timely, phased updating of the structure and organization of the hospital building, monitoring of promising tasks and the search for optimal ways to implement them. For most post-Soviet countries, the issue of reorganization, optimization and modernization of hospitals today is relevant. However, the direct transfer and use of foreign experience of these transformations is impossible - in each country, there are a number of positive and negative aspects in providing hospital services. There is no ideal model, the same way of organizing a hospital system cannot be used in its "pure form" - adaptation to the regional characteristics, social, economic and political capabilities of each particular state is necessary, as well as taking into account demographic indicators and the dynamics of progressive diseases. With all the modern world variety of ways to organize hospital systems, when designing new hospitals, it is worth considering the general trends: the enlargement of medical buildings, the formation of complexes; emphasis on the intensity of treatment, the use of day hospitals; individualization of design decisions, rejection of stereotypical hospital forms; the formation of an aesthetic space with healing potential; ecological approach and harmony with the environment. 


\section{REFERENCES}

[1] V. Pokrovskii. Small Medical Encyclopedia, Meditsina, Moscow, 1996.

[2] T. Miller. The Birth of the Hospital in the Byzantine Empire, Johns Hopkins University Press, Baltimore, 1996.

[3] D. Murphy. Where the Indus is Young - a Winter in Baltistan, John Murray, London, 1998.

[4] M. Hensher, N. Edwards, R. Stokes. International trends in the provision and utilisation of hospital care, British Medical Journal, Vol. 319, 84-88.

[5] M. Mckee. For debate does health care save lives, Croatian Medical Journal, Vol. 40, 123-128.

[6] M. Mckee, B. Jacobson. Public health in Europe, Lancet, Vol. 356, 66-70.

[7] R. Saltman, J. Figueras. European Health Care Reform: Analysis of Current Strategies, WHO Regional Publications, European Series, WHO Regional Office for Europe, Copenhagen, 1997.

[8] M. Shanahan, M. Brownell, N. Roos. The unintended and unexpected impact of downsizing: costly hospitals become more costly, Medical Care, Vol. 37, 23-34.

[9] M. Brownell, N. Roos, C. Burchill. Monitoring the impact of hospital downsizing on access to care and quality of care, Medical Care, Vol. 37, 35-50.

[10] A. Pollock, M. Dunnigan, D. Gaffney, D. Price, J. Shaoul. The private finance initiative: planning the 'new' NHS, Downsizing for the 21 st century, British Medical Journal, Vol. 319, 79-84.

[11] A. Street, J. Haycock. The economic consequences of reorganizing hospital services in Bishkek, Kyrgyzstan, Health Economist, Vol. 8, 53-64.

[12] I. V. Bulakh. The problematic field of tasks of reorganization of the network of children's medical institutions of Ukraine, Urban planning and territorial planning, Vol. 63, 45-51.

[13] I. V. Bulakh. Prerequisites for the reorganization of the network of children's medical institutions in Ukraine, Modern problems of architecture and urban planning, Vol. 47, 444-450.

[14] M. Mckee, A. Clarke, B. Tennison. Meeting local needs, British Medical Journal, Vol. 306, 602.

[15] M. Hensher, N. Edwards. Hospital provision, activity, and productivity in England since the 1980s, British Medical Journal, Vol. 319, 9-14.

[16] E. Khodosh. Hospital and hospital bed: developmental aspects, News of medicine and pharmacy, Vol. 3, 22-24.

[17] N. Edwards, A. Harrison. The hospital of the future: planning hospitals with limited evidence, A research and policy problem, British Medical Journal, Vol. 319, 13-63.

[18] I. V. Bulakh. Analysis of scientific researches in the aspect of architectural and urban planning of healthcare institutions, Scientific Bulletin of Construction, Vol. 93, 29-36.

[19] I. V. Bulakh, O. Kozakova, M. Didichenko. The Landscape Creation and Integration in Design and Urban Planning of
Medical Institutions, Landscape Architecture and Regional Planning, Vol. 4(4), 61-71. DOI: 10.11648/j.larp.20190404. 11.

[20] I. V. Bulakh. Prerequisites for artistic and aesthetic formation of the architectural environment of medical institutions, Scientific Bulletin of Construction, Vol. 94, 9-14.

[21] I. V. Bulakh, O. Kozakova, M. Didichenko, O. Chala. Health Care Architectural and Urban Planning Systems In The United States of America and France, International Journal of Innovative Technology and Exploring Engineering, Vol. 9(2), 1622-1627. DOI: 10.35940/ijitee. B7377.129219.

[22] K. Hillman. Restructuring hospital services, Medical Journal of Australia, Vol. 169, 239.

[23] Y. Hasenfeld, R. English. Human Service Organizations, Ann Arbor, University of Michigan Press, 1974.

[24] A. Wildavsky. Speaking Truth to Power: The Art and Craft of Policy Analysis, Little, Brown and Company, Boston, 1979.

[25] E. Mossialos, J. Le Grand. Health Care and Cost Containment in the European Union, Ashgate, Aldershot, 1999.

[26] P. Checkland, Systems Thinking, Systems Practice, Wiley, Chichester, 1981.

[27] V. Timokhin. Urban Development Architecture: 7 Books on Urban Theory, KNUCA, Kyiv, 2008.

[28] R. Porter. The Greatest Benefit to Mankind: A Medical History of Humanity from Antiquity to the Present, HarperCollins, London, 1997.

[29] L. Granshaw. Companion Encyclopaedia of the History of Medicine, Routledge, London, 1993.

[30] Club du Vieux Manoir, Saint-Louis de la Salpetriere, Nouvelles Editions Latines, Paris, 1977.

[31] N. Simon. La Pitie Salpetriere, Editions de l'Arbre, Paris, 1986.

[32] U. Trohler, C. PRULL. The rise of the modern hospital, Western Medicine, Oxford University Press, Oxford, 1997.

[33] R. Mcgrew. Encyclopaedia of Medical History, Macmillan, London, 1985.

[34] K. Hillman. The changing role for acute care hospitals, Medical Journal of Australia, Vol. 170, 32-39.

[35] I. V. Bulakh, O. Kozakova, M. Didichenko. The innovative trends in architecture and urban planning of health care institutions, International Journal of Innovative Technology and Exploring Engineering, Vol. 9(1), 317-323. DOI: 10.35940/ijitee.A4111.119119. https://www.ijitee.org/wp-c ontent/uploads/papers/v9i1/A4111119119.pdf

[36] I. V. Bulakh. Artistic and Aesthetic Formation and Evolution of Architectural and Urban Planning Space, Science and Innovation, Vol. 15, No. 5(5), 57-66. DOI: 10.15407/scine15.05.057 http://scinn-eng.org.ua/archive/15(5)/15(5)04

[37] I. V. Bulakh. Common Features of Architectural Design of 
the Medical Purpose Building, Science \& Technique, Vol. 18(4), 311-318. DOI: 10.21122/2227-1031-2019-18-4-311318. https://sat.bntu.by/jour/article/view/1990

[38] Department of Health, Shaping the Future NHS: Long Term Planning for Hospitals and Related Services, Department of Health, London, 2000.

[39] I. V. Bulakh. Urban Planning Organization and Development of Children's Medical Institutions in Ukraine, Journal of Regional and City Planning, Vol. 31, No. 1, 82-96. DOI: 10.5614/jpwk.2020.31.1.6 http://journals.itb.ac.id/ind ex.php/jpwk/article/view/12929

[40] I. V. Bulakh, O. Kozakova, M. Didichenko, O. Chala Architectural and urban planning system of health care in Germany and the United Kingdom, Space \& Form, Vol. 41, 141-148. DOI: 10.21005/pif.2020.41.C-02 http://www.pif.z ut.edu.pl//images/pdf/pif\%2041/DOI\%2010_21005_pif_20 20_41_C-02_Bulakh_et\%20al.pdf
[41] I. V. Bulakh, O. Kozakova, M. Didichenko, O. Chala. Sustainable futures in the context of architectural design of hospitals, The International Conference on Sustainable Futures: Environmental, Technological, Social and Economic Matters (ICSF 2020), E3S Web of Conferences, Vol. 166. DOI: 10.1051/e3sconf/202016608001 https://www.e3s-conferences.org/articles/e3sconf/abs/2020/ 26/e3sconf_icsf2020_08001/e3sconf_icsf2020_08001.html

[42] G. Kovalska, I. Merylova, I. Bulakh. Urban improvement of comprehensive schools and out of school educational establishments in Ukraine, International Journal of Innovative Technology and Exploring Engineering, Vol. 8(12), 1765-1770. DOI: 10.35940/ijitee.L3229.1081219. https://www.ijitee.org/wp-content/uploads/papers/v8i12/L3 2291081219.pdf

[43] V. Smilka. The Role of Monitoring in Sustainable Development, Baltic Journal of Real Estate Economics and Construction Management, Vol. 7(1), 245-254. 